\title{
Regional health care services and rates of lower extremity amputation related to diabetes and peripheral artery disease: an ecological study
}

\author{
Charles de Mestral MD PhD, Mohamad A. Hussain MD PhD, Peter C. Austin PhD, \\ Thomas L. Forbes MD, Atul Sivaswamy MSc, Ahmed Kayssi MD MPH, Konrad Salata MD PhD, \\ Harindra C. Wijeysundera MD PhD, Subodh Verma MD PhD, Mohammed Al-Omran MD MSc
}

Abstract

Background: The care necessary to prevent amputation from diabetes and peripheral artery disease (PAD) remains disjointed in many jurisdictions. To help inform integrated regional care, this study explores the correlation between regional health care services and rates of lower extremity amputation.

Methods: This ecological study included 14 administrative health regions in Ontario, Canada. All diabetes- or PAD-related major (above ankle) amputations (Apr. 1, 2007, to Mar. 31, 2017) were identified among residents 40 years of age and older. For each region, ageand sex-adjusted amputation rates were calculated as well as per capita counts of key health providers (podiatrists and chiropodists, as well as surgeons) and health care utilization among study patients in the year before the first major amputation (physician visits, publicly funded podiatry visits, emergency department visits, hospital admissions, home care nursing, minor amputation, limb revascularization).

Results: A total of 11658 patients with major amputation were identified (of whom $79.2 \%$ had diabetes and $96.5 \%$ had PAD). There was wide regional variation in amputation rates: 2.53 to 11.77 per 100000 person-quarters. At a regional level, the proportion of study patients who received revascularization showed the strongest negative correlation with amputation rates. The regional proportion of study patients who saw a vascular surgeon showed the strongest negative correlation with amputation rates, relative to other health provider visits. Other measures of health care utilization among patients correlated poorly with regional amputation rates, as did the regional provider counts. The results were similar when we restricted the analysis to diabetes-related amputations.

Interpretation: Amputation rates related to diabetes and PAD vary widely across Ontario. Access to vascular assessment and revascularization must be integrated into regional amputation prevention efforts.

eg amputation is one of the most feared complications of diabetes and peripheral artery disease (PAD). ${ }^{1,2}$ Accounting for over $80 \%$ of lower extremity amputations in Canada,,$^{3,4}$ diabetes- and PAD-related amputation can have a lasting impact on a person's mobility, mental health and life expectancy. ${ }^{1,2}$ Many diabetes- and PAD-related amputations are preventable with early recognition of a threatened limb and coordinated care by a range of health providers (podiatrists, chiropodists, primary care physicians, medical specialists, surgeons and nurses). Evidence-based guidelines outline best practice with respect to foot screening, wound care, infection management, and the assessment and treatment of arterial insufficiency. ${ }^{2,5-7}$ However, the care necessary to prevent and treat foot complications from diabetes and PAD remains disjointed in many jurisdictions. ${ }^{3,4}$

Patients with cancer or traumatic injury or who are in need of organ transplantation benefit from regional care pathways and dedicated centres of excellence in Canada. ${ }^{8-10}$ The same cannot be said for patients with diabetes or PAD at risk of limb loss. The frequency of amputations related to diabetes,

Competing interests: Subodh Verma reports receiving grants from AstraZeneca, Boehringer Ingelheim, Janssen, Merck, Novo Nordisk and Sanofi as well as personal fees from AstraZeneca, Boehringer Ingelheim, Eli Lilly, EOCI Pharmacomm, Janssen, Merck, Novo Nordisk, Sanofi and Sun Pharmaceuticals, during the conduct of the study. Subodh Verma also reports receiving grants from Amarin, Amgen, Bayer, Bristol Myers Squibb, HLS Therapeutics, Novartis and PhaseBio as well as personal fees from Amgen, Bayer, HLS Therapeutics and Novartis, outside the submitted work. No other competing interests were declared.

This article has been peer reviewed.

Correspondence to: Charles de Mestral, Charles.deMestral@ unityhealth.to

CMAJ Open 2020. DOI:10.9778/cmajo.20200048 
PAD or both is increasing. ${ }^{11}$ Integrated regional amputation prevention efforts may help save limbs for these patients. However, relative to other complications of diabetes and cardiovascular disease, there is limited health system-level insight into the clinical burden of lower extremity amputation and the effectiveness of prevention. In an effort to begin addressing this important knowledge gap, the objective of this study was to quantify the correlation between health services and amputation rates, at a regional level, in Ontario, Canada.

\section{Methods}

\section{Study design and overview}

This ecological study explored the correlation between regional health care services and rates of amputation related to diabetes or PAD in Ontario between Apr. 1, 2007, and Mar. 31, 2017. To calculate regional amputation rates as well as look back at health services received by patients who undergo amputations, we first defined a population-based cohort of all Ontarians aged 40 years and older who underwent major lower extremity amputation related to diabetes or PAD. In this patient population, we calculated the proportion who received specified health services within up to 1 year before the first major amputation. For each region, we calculated age- and sex-adjusted amputation rates as well as per capita counts of key health providers of foot care: podiatrists and chiropodists, and surgeons. We then quantified the correlation at the regional level between these measures and amputation rates.

\section{Setting}

Ontario has over 13 million residents living across over 1 million square kilometres. Most health services necessary to prevent amputation are covered under the single-payer public health care system, which was structured within 14 administrative health regions during the study period. Publicly funded services contributing to amputation prevention include primary and specialist physician care, emergency department and other hospital care, and in-home or in-community nursing care for wounds. However, outpatient foot care by nonphysician foot specialists, podiatrists and chiropodists, is mostly paid out of pocket by patients or through private insurers.

\section{Data sources}

The cohort of patients with amputations and their health care utilization before their first major amputation were captured from linked administrative health records for the province of Ontario. ${ }^{12}$ Eligible Ontario residents aged 40 years or older and their sex were identified in the Registered Persons Database. Amputation was identified from hospital admission records in the Canadian Institute for Health Information's Discharge Abstract Database. Other inpatient and outpatient health services received before amputation and their associated costs to the Ontario Ministry of Health were identified from the Discharge Abstract Database in addition to the National Ambulatory Care Reporting System database (all same-day surgery and emergency department encounters), the
Ontario Health Insurance Plan Claims Database (all physician claims and any publicly funded podiatry claims, which represent a small subset of services provided by podiatrists and chiropodists) and the Home Care Database (all publicly funded at-home or in-community nursing care).

The data sets were linked using unique encoded identifiers and analyzed at ICES. Deterministic linkage of these data sets has been validated for a variety of diagnoses and procedures including diabetes and lower extremity major amputation. ${ }^{13,14}$ Counts of podiatrists and chiropodists by region were publicly reported by the College of Chiropodists of Ontario. ${ }^{15}$ Physician provider counts per region were available from the ICES Physician Database. ${ }^{12}$

\section{Study population}

All Ontario residents at least 40 years of age with a hospital admission for major lower extremity amputation between Apr. 1, 2007, and Mar. 31, 2017, were identified on the basis of specified Canadian Classification of Health Intervention (CCI) codes (1VC93, 1VG93, 1VQ93, for below-, throughand above-knee amputation). Patients with type 1 or 2 diabetes were identified according to a validated algorithm for prevalent cases of diabetes using physician billing claims ${ }^{13}$ or the inclusion of a diagnosis code from the enhanced Canadian version of the International Statistical Classification of Diseases and Related Health Problems, 10th Revision (ICD-10-CA) for diabetes (E10-E14) on the hospital admission for the index amputation. Patients with PAD were identified on the basis of specified ICD-10-CA diagnosis codes for symptomatic PAD from the index amputation encounter or any hospital admission, same-day surgery or emergency department visit within the previous 3 years relative to the index amputation (Appendix 1, Supplemental Table S1, available at www.cmajopen.ca/ content/8/4/E659/suppl/DC1).

Patients under age 40 years and those with a most responsible diagnosis code on the hospital admission for the index amputation for traumatic injury, malignancy, congenital deformities, complications of an orthopedic prosthesis or other pathologies unrelated to diabetes or PAD were excluded from the study (Appendix 1, Supplemental Table S2). The age exclusion criterion was applied because amputation related to diabetes and PAD is extremely rare in people under 40 years of age. ${ }^{6}$ Certain characteristics of the study patients were also captured, including age, sex, rural residence and income quintile. Using a 3-year look-back window relative to the index amputation date, we also captured a comorbidity index based on weighted John Hopkins Aggregated Diagnosis Groups validated for prediction of 1-year mortality among Ontarians. ${ }^{16-18}$ A similar cohort of Ontario residents with amputations and their characteristics have been previously described. ${ }^{11}$

\section{Region-specific amputation rates}

Given changes in the Ontario and region-specific populations over time, major amputation rates were first calculated for individual quarters from 2007 to 2017. The rate numerator was the number of major amputations within each region 
based on the region of residence of each study patient. Region of residence was selected rather than the region of hospital admission because interregional transfer is common for urgent vascular surgical care in Ontario. Given the long study period and the fact that 2 legs may be at risk, multiple major amputations in the same patient may occur, but a limit was set to 1 major amputation count per patient per quarter. The rate denominator included all Ontario residents aged 40 years or older within a given region at the start of each quarter. Restricting the rate denominator to patients known to have diabetes or PAD is unlikely to reflect the true number of Ontarians at risk of amputation because for some patients who undergo amputations, their first presentation with diabetes or PAD is a nonsalvageable foot complication treated with amputation.

For each quarter, direct standardization of the regional rates was performed on age ( $40-70 \mathrm{yr}, \geq 70 \mathrm{yr}$ ) and sex (male, female). Previous analyses have suggested that the same regions have remained high and low outliers with respect to amputation rates for diabetes or PAD over the study period..$^{19-21}$ An average quarterly rate for the 10-year study period was therefore calculated for each region. The earlier years of the study period remain reflective of current practice in the opinion of the authors.

\section{Health provider counts, health service utilization, health care costs}

On the premise that access and use of potentially preventive health services may influence amputation rates in certain regions, we defined region-specific measures of potential access and, among study patients, realized use of health care services before amputation. We considered specific health services usually involved in the treatment of foot complications from diabetes and PAD (e.g., revascularization, orthopedic surgeon visit, per capita count of podiatrists and chiropodists). We also considered clinical interactions or health services not specific to diabetes or PAD (e.g., any hospital admission) because these represent an opportunity to recognize a threatened limb (e.g., a foot ulcer may be identified during hospital admission for pneumonia or a family physician visit).

Counts (per 100000 residents aged at least $40 \mathrm{yr}$ ) of vascular surgeons, general surgeons, orthopedic surgeons, and podiatrists and chiropodists were made for each region in fiscal year 2013. Health service utilization was measured among study patients as the proportion of study patients who, up to 1 year before the date of hospital admission for the index amputation, had any of the following: physician visits, publicly funded podiatry visits, emergency department visits, hospital admissions, outpatient nursing care, endovascular or open surgical revascularization (e.g., endovascular angioplasty or stenting, open surgery), or minor (below ankle) amputations.

Physician visits included those to a family physician, vascular surgeon, general surgeon, orthopedic surgeon or other specialist. Physician and podiatry visits within 30 days before the index amputation admission were not counted because visits so close to amputation are more likely to reflect the assessment and determination of a nonsalvageable limb rather than to represent an opportunity to avoid amputation. In all instances of chronic limb-threatening ischemia, revascularization should occur within 4 weeks of diagnosis, with an initial trial of medical management (infection control, wound care and off-loading) indicated in certain circumstances of low and intermediate limb threat. ${ }^{6,7}$ As such, provider encounters with a meaningful opportunity to prevent major amputation would probably have begun at least 30 days before amputation. Minor amputation and revascularization, identified on the basis of CCI codes (Appendix 1, Supplemental Table S3), were captured within 1 year before major amputation but also on the admission for the index major amputation, because same-admission revascularization or toe amputation probably reflects attempted limb salvage.

Finally, as a broad measure of all publicly funded health care services received before amputation, total health care costs from the perspective of the Ontario Ministry of Health were captured within 1 year before the hospital admission for the index amputation. Costs included those attributable to hospital care (acute care, rehabilitation, chronic continuing care), physician services, publicly funded podiatry services, outpatient procedures, outpatient testing (e.g., imaging, blood tests), outpatient nursing and allied health home care, assistive devices (e.g., walker, hearing aid) and, for patients aged at least 65 years, outpatient medications. Person-level cost was estimated according to previously described methodology using the aforementioned administrative health databases (see Appendix 1 for costing methodology)..$^{22}$

In brief, hospital care costs were estimated from the weighted allocation of global hospital budgets. For example, every acute care hospital admission was assigned a resource intensity weight (RIW) value on the basis of the most responsible diagnosis, patient age, comorbidity burden, interventions during hospital admission and length of stay. A year-specific cost per weighted case (CPWC) is calculated by dividing the global hospital budget for acute care by the sum of RIWs for all hospital admissions that year. The cost of a specific patient's hospital admission is then estimated as the product of the RIW and the CPWC. Physician services, outpatient nursing and allied health services, outpatient medications and testing costs were estimated from per-unit costs. Costs were standardized to 2017 Canadian dollars.

\section{Statistical analysis}

The magnitude and direction (positive or negative) of the linear correlation between regional average amputation rate and health services measures was quantified with the Pearson correlation coefficient. On the basis of effect size considerations suggested by Cohen, the magnitude of specific correlations can be interpreted according to the following criteria (where $r$ denotes the absolute value of the coefficient): $0.1<r \leq 0.3$ denotes weak correlation; $0.3<r \leq 0.5$ denotes moderate correlation; $r>0.5$ denotes strong correlation. ${ }^{23}$ A secondary analysis was performed repeating the analysis on the basis of amputations related to diabetes (i.e., excluding those study patients with PAD but not diabetes). 


\section{Ethics approval}

The use of data in this project was authorized under section 45 of Ontario's Personal Health Information Protection Act, which does not require review by a research ethics board.

\section{Results}

A total of 11658 patients were included in the cohort of patients with major amputations, of whom 11249 (96.5\%) had PAD and $9232(79.2 \%)$ had diabetes (Table 1). The average province-wide rate of major amputation related to diabetes or PAD was 5.31 per 100000 person-quarters. At the regional level, the age- and sex-adjusted rates of major amputation ranged from 2.53 to 11.77 per 100000 person-quarters (Figure 1 and Appendix 2, Supplemental Table S1, available at www.cmajopen.ca/content/8/4/E659/supp1/DC1). Regions with the highest amputation rates had a larger proportion of their residents with amputations living in rural areas and in the lowest provincial income quintile. There was no meaningful regional difference in the overall comorbidity level of the study patients, on the basis of comorbidity index or inhospital mortality associated with major amputation (Appendix 2, Supplemental Table S2).

The regional count of vascular surgeons and of podiatrists and chiropodists per 100000 residents was inversely related with amputation rates; however, there was low correlation between regional counts of all health providers and amputation rates (Table 2 and Appendix 2, Supplemental Table S3).

With respect to regional measures of health service utilization among patients with amputations, the regional proportion of such patients who received endovascular or open revascularization showed the strongest negative correlation with regional amputation rates (Table 2). Among provider visits, a vascular surgeon visit showed the strongest negative correlation with regional amputation rates (Table 2). Previous hospital admission, emergency department visit, receipt of outpatient at-home or in-community nursing care and total publicly funded health care costs all correlated poorly with

\section{Table 1: Characteristics of patients with major lower} extremity amputation in the study cohort

\begin{tabular}{|lc|}
\hline Characteristic & $\begin{array}{c}\text { No. (\%) of patients* } \\
n=11658\end{array}$ \\
\hline Age, yr, mean \pm SD & $69.7 \pm 12.4$ \\
\hline Male sex & $7767(66.6)$ \\
\hline Lowest provincial income quintile & $3337(29.0)$ \\
\hline Rural residence & $2020(17.3)$ \\
\hline $\begin{array}{l}\text { Aggregated diagnosis group } \\
\text { comorbidity index, median (IQR) }\end{array}$ & $12(4$ to 21) \\
\hline Peripheral artery disease & $11249(96.5)$ \\
\hline Diabetes & $9232(79.2)$ \\
\hline $\begin{array}{l}\text { Note: IQR }=\text { interquartile range, SD }=\text { standard deviation. } \\
\text { *Unless indicated otherwise. }\end{array}$ \\
\hline
\end{tabular}

regional amputations rates (Table 2 and Appendix 2, Supplemental Tables S4-S6).

The findings were similar when we considered only amputations related to diabetes, with the exception of a significant negative correlation with outpatient at-home or incommunity nursing care (Appendix 3, Supplemental Tables $\mathrm{S} 1-\mathrm{S} 7$, available at www.cmajopen.ca/content/8/4/E659/ suppl/DC1).

\section{Interpretation}

This population-based study of major amputations related to diabetes or PAD sought to quantify the correlation between regional amputations rates and regional rates of health services across Ontario. There were 2 main findings. First, there was wide regional variation in amputation rates, with the highest rates seen in more rural and northern regions. Second, vascular surgeon assessment and receipt of revascularization to address arterial insufficiency among people who eventually underwent amputation was strongly correlated, at a regional level, with lower amputation rates.

Previous analyses have consistently documented high amputation rates in residents of northern Ontario. ${ }^{19-21}$ In Canadian provinces as well in the United States and Australia, residents of rural regions and Indigenous communities have higher amputation rates related to diabetes. ${ }^{24-28}$ Compared with people with amputations in low-rate regions, those in northern regions of Ontario had a similar comorbidity level and received primary care and many health services with similar frequency before amputation. However, potentially limbsaving treatments were less commonly performed, most notably revascularization. As with myocardial infarction and stroke, ${ }^{29}$ geography appears to influence the clinical outcome of patients with a threatened limb because of diabetes or PAD.

Across all contexts of practice, there are shared principles that apply to amputation prevention: patients with diabetes or PAD should check their feet daily for wounds, foot assessment should be completed at least annually by a trained health care provider who can also provide patient education, and foot wounds or infection should be promptly evaluated by a knowledgeable care provider who works within or is supported by a multidisciplinary foot care team..$^{2,5-7}$ Our study, however, demonstrates the need to address the substantial regional disparities in amputation burden across Ontario. Solutions to reduce amputation rates must be tailored to regional circumstances (e.g., Loewen and colleagues' Sioux Lookout Diabetic Foot Ulcer Protocol ${ }^{27}$ ). In addition to health system analyses such as ours and comparative effectiveness research, qualitative research of the patient experience in different regions and social contexts is critical to developing effective regional amputation prevention programs.

Amputation prevention requires a range of expertise that no individual health provider can offer alone. International and Canadian studies support multidisciplinary care to prevent and treat foot complications of diabetes and peripheral atherosclerosis. ${ }^{30-33}$ Models of collaborative care must bring together key domains of expertise necessary to treat a 


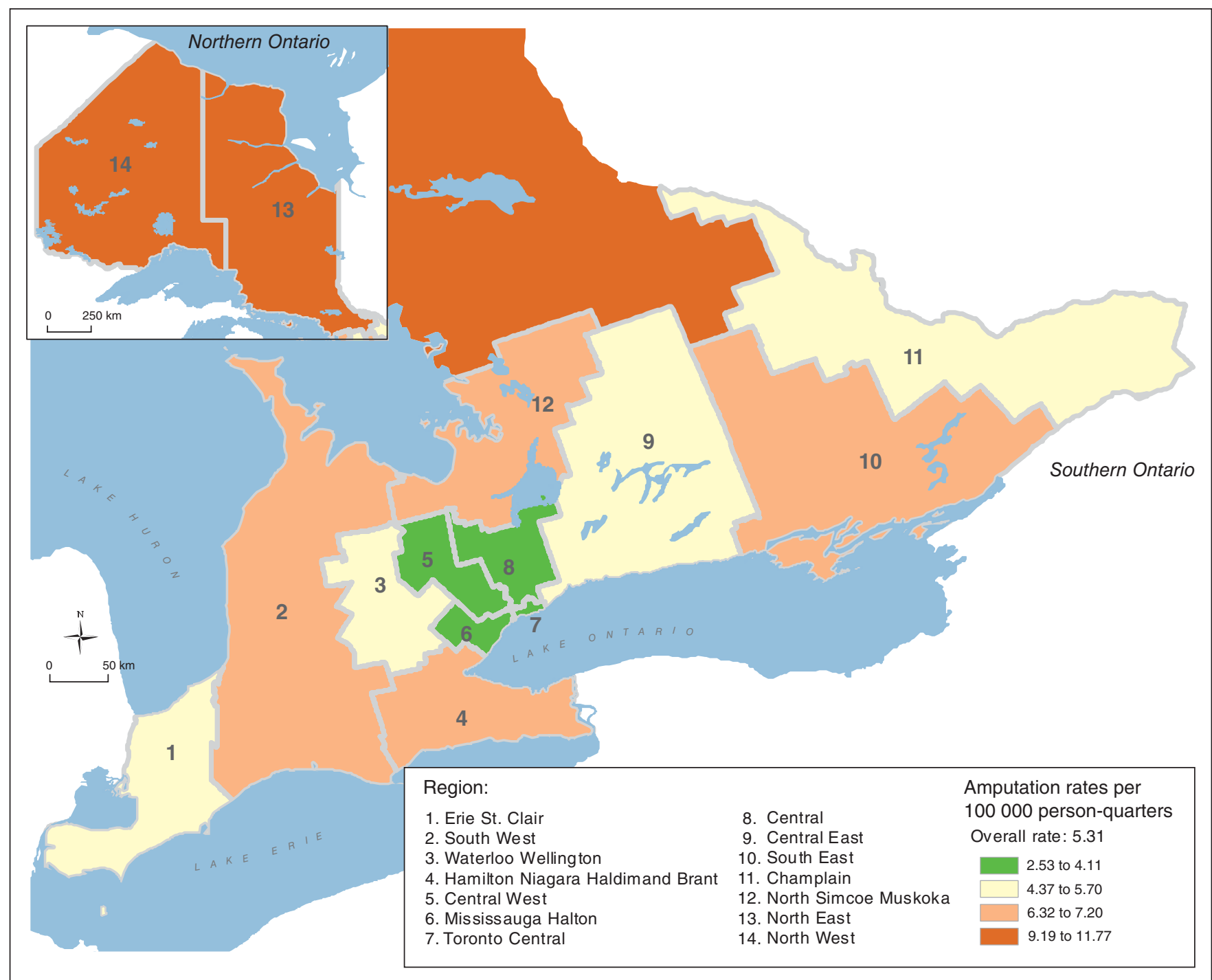

Figure 1: Age- and sex-standardized rates of major amputations related to diabetes or peripheral artery disease among residents aged 40 years or older across Ontario, 2007-2017.

threatened limb effectively. All patients require tailored medical or surgical treatment of arterial atherosclerosis (or both), medical or surgical management of any foot infection (or both), and wound care including assessment and treatment of contributory pathologic foot biomechanics. The toe and flow model structured around the close collaboration of podiatry and vascular surgery, with support from other specialties (e.g., endocrinology, infectious disease, general internal medicine, hematology, orthopedic surgery, plastic surgery, interventional radiology and physiatry) is a well-known example of foot care team structure. ${ }^{34}$ More commonly seen in Canada, medical teams treating a broad range of wounds can also be supported by hospital-based surgical expertise to address infection, foot deformity and ischemia. ${ }^{35-37}$

Regardless of the structure of foot care teams, our analysis confirms the integral importance of assessing and treating arterial insufficiency to prevent limb loss. Not all patients with diabetes or PAD can realistically be screened and surveyed by a multidisciplinary team. As the prevalence of diabetes increases, primary care physicians will increasingly need to triage their patients at highest risk for referral to foot care teams. Foot screening and referral pathways for foot care for people with diabetes have been implemented in Alberta, Nova Scotia, Prince Edward Island and Saskatchewan. ${ }^{38-41}$ Other health systems internationally have implemented national foot screening programs (e.g., Scotland ${ }^{42}$ ) and defined a national foot care strategy (e.g., Australia ${ }^{43}$ ). However, over $80 \%$ of Canadians living in Ontario, Quebec and other provinces and territories must rely on informal pathways of care that may fail patients, particularly those who are marginalized or who have medically complex needs.

Our study most directly supports improving key areas of care to reduce amputation rates: screening for PAD in patients with diabetes, vascular consultation when PAD is present, and timely access to and consideration for revascularization. The results also support the imperative of integrating 


\begin{tabular}{|c|c|c|}
\hline Measure & $\begin{array}{l}\text { Range of values } \\
\text { across } 14 \text { regions }\end{array}$ & $\begin{array}{l}\text { Pearson correlation } \\
\text { coefficient }(95 \% \mathrm{Cl})^{*}\end{array}$ \\
\hline \multicolumn{3}{|l|}{ No. of health providers per capita within each region $†$} \\
\hline Vascular surgeons & 0 to 1.9 & $-0.44(-0.78$ to 0.14$)$ \\
\hline Chiropodists and podiatrists & 3.7 to 36.6 & $-0.38(-0.75$ to 0.20$)$ \\
\hline Orthopedic surgeons & 5.5 to 15.0 & $0.17(-0.40$ to 0.64$)$ \\
\hline Vascular, general and orthopedic surgeons & 14.1 to 33.4 & $0.26(-0.32$ to 0.69$)$ \\
\hline General surgeons & 8.3 to 16.5 & $0.42(-0.14$ to 0.78$)$ \\
\hline \multicolumn{3}{|c|}{$\begin{array}{l}\text { Health provider visit among study patients (at least } 1 \text { visit within } 1 \mathrm{yr} \text { before hospital admission for index } \\
\text { amputation) } \ddagger\end{array}$} \\
\hline Vascular surgeon & 5.5 to 58.8 & $-0.66(-0.88$ to -0.17$)$ \\
\hline Publicly funded podiatrist§ & 0.0 to 8.4 & $-0.34(-0.73$ to 0.25$)$ \\
\hline Vascular, general or orthopedic surgeon & 57.4 to 81.9 & $-0.29(-0.71$ to 0.29$)$ \\
\hline Primary care physician & 90.4 to 97.1 & $0.05(-0.50$ to 0.56$)$ \\
\hline Orthopedic surgeon & 16.4 to 33.2 & $0.25(-0.33$ to 0.68$)$ \\
\hline $\begin{array}{l}\text { Specialist physician (excluding vascular, general and orthopedic } \\
\text { surgeons) }\end{array}$ & 91.0 to 95.4 & $0.43(-0.15$ to 0.78$)$ \\
\hline General surgeon & 10.1 to 43.1 & $0.54(-0.01$ to 0.82$)$ \\
\hline \multicolumn{3}{|c|}{ Health services among study patients (within 1 yr before hospital admission for index amputation) } \\
\hline Endovascular or open vascular intervention & 5.7 to 27.5 & $-0.84(-0.95$ to -0.54$)$ \\
\hline Endovascular intervention & 2.7 to 18.5 & $-0.82(-0.94$ to -0.49$)$ \\
\hline Open vascular intervention & 4.4 to 19.5 & $-0.51(-0.81$ to 0.05$)$ \\
\hline Outpatient nursing care & 48.7 to 79.6 & $-0.47(-0.79$ to 0.10$)$ \\
\hline Total health care costs, $\$$ & 45103 to 69483 & $-0.39(-0.76$ to 0.19$)$ \\
\hline Hospital admission (at least 1 ) & 58.2 to 70.8 & $-0.10(-0.60$ to 0.45$)$ \\
\hline Minor amputation & 8.2 to 20.4 & $0.34(-0.25$ to 0.73$)$ \\
\hline Emergency department visit (at least 1) & 83.6 to 91.2 & $0.50(-0.06$ to 0.81$)$ \\
\hline \multicolumn{3}{|l|}{ Intervention during hospital admission for index amputation } \\
\hline Endovascular or open vascular intervention & 4.2 to 21.0 & $-0.81(-0.93$ to -0.46$)$ \\
\hline Open vascular intervention & 1.8 to 13.7 & $-0.74(-0.91$ to -0.32$)$ \\
\hline Endovascular intervention & 3.0 to 13.4 & $-0.65(-0.87$ to -0.16$)$ \\
\hline \multicolumn{3}{|c|}{$\begin{array}{l}\text { Note: } \mathrm{Cl}=\text { confidence interval. } \\
\text { *Negative coefficient denotes an inverse linear relationship. The magnitude of specific correlations can be interpreted according to the following } \\
\text { criteria (where } r \text { is the absolute value of the coefficient): } 0.1<r \leq 0.3 \text { denotes weak correlation; } 0.3<r \leq 0.5 \text { denotes moderate correlation; } r> \\
0.5 \text { denotes strong correlation. }{ }^{22} \\
+ \text { Counts of providers per } 100000 \text { residents } \geq 40 \text { years of age. } \\
\text { tExcluding } 30 \text { days before amputation. } \\
\text { \$Most podiatry and chiropody services are not publicly funded in Ontario. }\end{array}$} \\
\hline
\end{tabular}

vascular surgeons in the care of foot complications in patients with diabetes. Formalizing regional amputation prevention pathways should help explicitly identify key providers and promote the integration of multidisciplinary care. Furthermore, defining the impact of amputation prevention pathways currently in place in Nova Scotia and Alberta is an urgent research priority.

\section{Limitations}

Certain limitations of our analysis should be made explicit. We did not have information on the extent of foot wound(s), infection or severity of foot ischemia before amputation. As a result, we cannot quantify how many amputations in high-rate regions could have been prevented if the same patients lived in low-rate regions. In addition to disease severity, we could not adjust regional amputation rates for important confounders such comorbidity burden, smoking, social and economic marginalization, Indigenous status or ethnicity. ${ }^{2,5-7}$

The date on which a limb became threatened cannot be captured using existing provincial administrative data for 2 main reasons. The first is that physician billing claims cannot reliably identify when the initial diagnosis of a threatened 
limb is made. The second is that emergency department visits and hospital admissions do not necessarily reflect the initial diagnosis of a threatened limb; they more often reflect worsening of a foot wound (e.g., emergency department visit for acute infection of a foot wound treated on an outpatient basis for $8 \mathrm{mo}$ ) or the effort to prevent amputation (e.g., hospital admission for revascularization). As a result, the extent to which delayed presentation or diagnosis contributes to variation in regional amputation rates remains uncertain. Whether foot examination and risk factor assessment was performed during a given family physician visit, emergency department visit or hospital admission is unknown. As a result, while these clinical encounters represent an opportunity for early recognition of a threatened limb, the potential correlation between such non-specific health service measures and amputation rates would reasonably be expected to be low.

Provider counts by specialty are based on information available to the Ministry of Health about providers' specialties. However, some vascular surgeons may have billed as general surgeons, leading to an underestimation of the number of vascular surgeons per capita in a region. The correlation between the care delivered by podiatrists and chiropodists and regional amputation rates could not be well documented in our analysis. Assessments (foot examination, footwear evaluation) and interventions (e.g., debridement, prescription of offloading footwear) by podiatrists or chiropodists are not publicly funded in Ontario except in the case of podiatrists and chiropodists who work in a few family health teams and wound care clinics and a minority of podiatrists and chiropodists who can directly submit claims (yearly maximum $\$ 135$ per patient) to the Ontario Health Insurance Plan. It is probable that the financial barrier to accessing private podiatry and chiropody services contributes to the limited access to foot care and amputation prevention for many Ontarians with diabetes or PAD. Finally, given the ecological nature of this study, the effectiveness of specific health services in preventing amputation at the patient level in Ontario has not be directly demonstrated.

\section{Conclusion}

Diabetes- and PAD-related major amputation rates differed considerably by geographic region in Ontario. Regional rates of assessment by a vascular surgeon and receipt of revascularization were inversely correlated with regional rates of amputation. These data justify and inform the integrated regional foot care efforts necessary to prevent amputations from diabetes and PAD.

\section{References}

1. Weisz, T. Some assembly required: Foot care for persons with diabetes in Ontario, Canada. Can 7 Diabetes 2016;49:492-95

2. Botros M, Kuhnke J, Embil J, et al. Foundations of best practice for skin and wound management: best practice recommendations for the prevention and management of diabetic foot ulcers. North York (ON): Wounds Canada (Canadian Association of Wound Care); 2019:1-68. Available: www.woundscanada.ca/ docman/public/health-care-professional/bpr-workshop/895-wc-bpr-prevention -and-management-of-diabetic-foot-ulcers-1573r1e-final/file (accessed 2019 Apr. 15)

3. Imam B, Miller WC, Finlayson HC, et al. Incidence of lower limb amputation in Canada. Can $\mathcal{F}$ Public Health 2017;108:e374-80.
4. Kayssi A, de Mestral C, Forbes TL, et al. A Canadian population-based description of the indications for lower-extremity amputations and outcomes. Can 7 Surg 2016;59:99-106.

5. Diabetes Canada Clinical Practice Guidelines Expert Committee; Embil JM, Albalawi Z, Bowering K, et al. Diabetes Canada 2018 clinical practice guidelines: foot care. Can $\mathcal{F}$ Diabetes 2018;42:S222-7.

6. Conte MS, Bradbury AW, Kolh P, et al. Global vascular guidelines on the management of chronic limb-threatening ischemia. 7 Vasc Surg 2019;69: 3S-125S.e40.

7. Schaper NC, van Netten JJ, Apelqvist J, et al.; International Working Group on the Diabetic Foot (IWGDF). 2019 IWGDF guidelines on the prevention and management of diabetic foot disease. International Working Group on the Diabetic Foot (IWGDF); 2019. Available: https://iwgdfguidelines .org/wp-content/uploads/2019/05/IWGDF-Guidelines-2019.pdf (accessed 2019 Aug. 1).

8. MacKenzie EJ, Rivara FP, Jurkovich GJ, et al. A national evaluation of the effect of trauma-center care on mortality. N Engl 7 Med 2006;354:366-78.

9. Finley C, Schneider L, Shakeel S, et al. Approaches to bigh-risk, resource intensive cancer surgical care in Canada. Toronto: Canadian Partnership Against Cancer. Available: www.longwoods.com/articles/images/high-risk-resource-intensive -cancer-surgical.pdf (accessed 2019 Apr. 15).

10. Organ donation and transplantation in Canada: system progress report 2006-2015. Ottawa: Donation and Transplantation, Canadian Blood Services; 2016. Available: https://blood.ca/sites/default/files/ODT_Report.pdf (accessed 2019 Apr. 15)

11. Hussain MA, Al-Omran M, Salata K, et al. Population-based secular trends in lower extremity amputation for diabetes and peripheral artery disease. CMAJ 2019;191:E955-61.

12. Dataset repository. Toronto: ICES. Available: https://datadictionary.ices. on.ca/Applications/DataDictionary/Default.aspx (accessed 2019 Apr. 15).

13. Hux JE, Ivis F, Flintoft V, et al. Diabetes in Ontario: determination of prevalence and incidence using a validated administrative data algorithm. Diabetes Care 2002;25:512-6.

14. Juurlink D, Preyra C, Croxford R, et al. Canadian Institute for Health Information Discharge Abstract Database: a validation study. Toronto: ICES; 2006.

15. Review of the chiropody and podiatry professions. Toronto: College of Chiropodists of Ontario; 2014. Available: http://cocoo.on.ca/pdf/cocoo_hprac_ submission_28nov2014.pdf (accessed 2019 Apr. 15).

16. Wilkins R. Use of postal codes and addresses in the analysis of health data. Health Rep 1993;5:157-77.

17. Kralj B. Measuring rurality — RIO2008_BASIC: methodology and results. Toronto: Ontario Medical Association; 2009. Available: https://content.oma. org//wp-content/uploads/2008rio-fulltechnicalpaper.pdf (accessed 2019 Mar. 1).

18. Austin PC, Van Walraven C. The mortality risk score and the ADG score: two points-based scoring systems for the Johns Hopkins aggregated diagnosis groups to predict mortality in a general adult population cohort in Ontario, Canada. Med Care 2011;49:940-7.

19. Booth GL, Polsky JY, Gozdyra P, et al. Regional measures of diabetes burden in Ontario. Toronto: ICES; 2012.

20. A vascular services quality strategy for Ontario: observations and recommendations. Toronto: Cardiac Care Network of Ontario; 2012.

21. Hussain MA, Al-Omran M, Salata K, et al. A call for integrated foot care and amputation prevention pathways for patients with diabetes and peripheral arterial disease across Canada. Can 7 Public Health 2019;110:253-5.

22. Wodchis WP, Bushmeneva K, Nikitovic M, et al. Guidelines on person-level costing using administrative databases in Ontario. Working paper series. Vol. 1. Toronto: Health System Performance Research Network; 2013.

23. Cohen J. Statistical power analysis for the behavioral sciences. Hillsdale (NJ): Lawrence Erlbaum Associates; 1988.

24. Martens PJ, Martin BO, Neil J, et al. Diabetes and adverse outcomes in a First Nations population: association with healthcare access and socioeconomic and geographic factors. Can 7 Diabetes 2007;31:223-32.

25. Skrepnek GH, Mills JL Sr, Armstrong DG. A diabetic emergency one million feet long: disparities and burdens of illness among diabetic foot ulcer cases within emergency departments in the United States, 2006-2010. PLoS One 2015;10:e0134914.

26. Burden of lower limb amputations due to diabetes in Australia: Australian burden of disease study 2011. Australian Burden of Disease Study 2011. Series no. 10. BOD 11. Canberra (AU): Australian Institute of Health and Welfare; 2017.

27. Loewen K, Vigliarolo J, Lance B. Rates of diabetes-related lower-limb amputation in northwestern Ontario: an incidence study and introduction of a standardized diabetic foot ulcer management protocol. Can 7 Rural Med 2017;22:100-7.

28. Shah BR, Frymire E, Jacklin K, et al. Peripheral arterial disease in Ontario First Nations people with diabetes: a longitudinal population-based cohort study. CMA7 Open 2019;7:E700-5.

29. Tu JV, Chu A, Maclagan L, et al. Regional variations in ambulatory care and incidence of cardiovascular events. CMA7 2017;189:E494-501.

30. Rose G, Duerksen F, Trepman E, et al. Multidisciplinary treatment of diabetic foot ulcers in Canadian Aboriginal and non-Aboriginal people. Foot Ankle Surg 2008;14:74-81. 
31. Chiu CC, Huang CL, Weng SF, et al. A multidisciplinary diabetic foot ulcer treatment programme significantly improved the outcome in patients with infected diabetic foot ulcers. 7 Plast Reconstr Aesthet Surg 2011;64:867-72.

32. Morbach S, Kersken J, Lobmann R, et al. The German and Belgian accreditation models for diabetic foot services. Diabetes Metab Res Rev 2016;32(Suppl 1):318-25.

33. Joret MO, Osman K, Dean A, et al. Multidisciplinary clinics reduce treatment costs and improve patient outcomes in diabetic foot disease. 7 Vasc Surg 2019;70:806-14.

34. Rogers LC, Andros G, Caporusso J, et al. Toe and flow: essential components and structure of the amputation prevention team. 7 Am Podiatr Med Assoc 2010;100:342-8.

35. Ogrin R, Houghton PE, Thompson GW. Effective management of patients with diabetes foot ulcers: outcomes of an interprofessional diabetes foot ulcer team. Int Wound 7 2015;12:377-86.

36. Roth-Albin I, Mai SHC, Ahmed Z, et al. Outcomes following advanced wound care for diabetic foot ulcers: a Canadian study. Can 7 Diabetes 2017;41:26-32.

37. Somayaji R, Elliott JA, Persaud R, et al. The impact of team based interprofessional comprehensive assessments on the diagnosis and management of diabetic foot ulcers: a retrospective cohort study. PLoS One 2017; 12:e0185251.

38. Diabetes foot care clinical pathway. Edmonton: Alberta Heath Services; 2017. Available: www.albertahealthservices.ca/scns/Page10321.aspx (accessed 2019 Aug. 1).

39. Lower extremity wound patbway. Regina: Saskatchewan Health Authority. Available: www.sasksurgery.ca/provider/lowerextremitywound.html (accessed 2019 Aug. 1).

40. Foot care. Halifax: Nova Scotia Health Authority. Available: www.cdha.nshealth. ca/diabetes-care-program-nova-scotia/foot-care (accessed 2019 Aug. 1).

41. Mutch K, Dewar D. Implementing a provincial diabetic foot screening program. 7 Wound Ostomy Continence Nurs 2015;42:439-42.

42. Stang D, Leese GP. The Scottish Diabetes Foot Action Group 2016 update of the Diabetic Foot Risk Stratification and Triage System. Diabetic Foot 7 2016;19:182-6.

43. Van Netten JJ, Lazzarini PA, Fitridge R, et al. Australian diabetes-related foot disease strategy 2018-2022: the first step towards ending avoidable amputations within a generation. Brisbane (AU): Diabetic Foot Australia, Wound Management CRC; 2017.

Affiliations: Li Ka Shing Knowledge Institute (de Mestral, Hussain, Salata, Verma, Al-Omran), St. Michael's Hospital; ICES Central (de Mestral, Austin, Sivaswamy, Salata); Department of Surgery (de Mestral, Hussain, Forbes, Kayssi, Salata, Verma, Al-Omran), Faculty of Medicine, University of Toronto; Sunnybrook Research Institute
(Austin, Kayssi, Wijeysundera), Sunnybrook Health Sciences Centre; Peter Munk Cardiac Centre (Austin, Forbes), University Health Network; Department of Medicine (Wijeysundera), Faculty of Medicine, University of Toronto; Diabetes Action Canada (de Mestral, Forbes, Kayssi, Al-Omran), Toronto, Ont.

Contributors: Charles de Mestral, Mohammad Hussain, Peter Austin and Mohammed Al-Omran conceived the study and designed the methodology. Charles de Mestral, Mohamad Hussain and Atul Sivaswamy curated the data, which Charles de Mestral and Atul Sivaswamy analyzed. All authors contributed to interpreting the data, writing the manuscript and revising it critically for important intellectual content. All authors approved the final version to be published and agreed to be accountable for all aspects of the work.

Funding: This project was funded by a Heart and Stroke Richard Lewar Centre for Excellence Award and the Li Ka Shing Knowledge Institute of St. Michael's Hospital. Charles de Mestral is supported by an Ontario Early Researcher Award. Peter Austin is supported by a Mid-Career Investigator Award from the Heart and Stroke Foundation. Harindra Wijeysundera holds a Canada Research Chair in structural heart disease policy and outcomes. Subodh Verma holds a Canada Research Chair in cardiovascular surgery.

Data sharing: The data set from this study is held securely in coded form at ICES. While data-sharing agreements prohibit ICES from making the data set publicly available, access may be granted to those who meet pre-specified criteria for confidential access, available at https://www.ices.on.ca/DAS.

Disclaimer: This study was supported by the Institute for Clinical Evaluative Sciences (ICES), which is funded by an annual grant from the Ontario Ministry of Health and Long-Term Care (MOHLTC). The opinions, results and conclusions reported in this paper are those of the authors and are independent from the funding sources. No endorsement by ICES or the Ontario MOHLTC is intended or should be inferred. Parts of this material are based on data and information compiled and provided by the Canadian Institute for Health Information (CIHI). The opinions, results and conclusions reported in this paper are those of the authors and are independent from the funding sources and CIHI.

Supplemental information: For reviewer comments and the original submission of this manuscript, please see www.cmajopen.ca/content/8/4/ E659/suppl/DC1. 